\title{
CAMA
}

Centre for Applied Macroeconomic Analysis

\section{Oil Prices and the Global Economy: Is It Different This Time Around?}

\section{CAMA Working Paper 56/2016 September 2016}

Kamiar Mohaddes

Faculty of Economics and Girton College, University of Cambridge and Centre for Applied Macroeconomic Analysis, ANU

\section{Hashem Pesaran}

Department of Economics \& USC Dornsife INET, University of Southern California Trinity College, Cambridge, UK

\section{Abstract}

The recent plunge in oil prices has brought into question the generally accepted view that lower oil prices are good for the US and the global economy. In this paper, using a quarterly multi-country econometric model, we first show that a fall in oil prices tends relatively quickly to lower interest rates and inflation in most countries, and increase global real equity prices. The effects on real output are positive, although they take longer to materialize (around 4 quarters after the shock). We then re-examine the effects of low oil prices on the US economy over different sub-periods using monthly observations on real oil prices, real equity prices and real dividends. We confirm the perverse positive relationship between oil and equity prices over the period since the 2008 financial crisis highlighted in the recent literature, but show that this relationship has been unstable when considered over the longer time period of 1946-2016. In contrast, we find a stable negative relationship between oil prices and real dividends which we argue is a better proxy for economic activity (as compared to equity prices). On the supply side, the effects of lower oil prices differ widely across the different oil producers, and could be perverse initially, as some of the major oil producers try to compensate their loss of revenues by raising production. Taking demand and supply adjustments to oil price changes as a whole, we conclude that oil markets equilibrate but rather slowly, with large episodic swings between low and high oil prices. 


\section{Keywords}

Oil prices, equity prices, dividends, economic growth, oil supply, global oil markets, and international business cycle.

\section{JEL Classification}

C32, E17, E32, F44, F47, O51, Q43

\section{Address for correspondence:}

(E) cama.admin@anu.edu.au

\section{ISSN 2206-0332}

The Centre for Applied Macroeconomic Analysis in the Crawford School of Public Policy has been established to build strong links between professional macroeconomists. It provides a forum for quality macroeconomic research and discussion of policy issues between academia, government and the private sector.

The Crawford School of Public Policy is the Australian National University's public policy school, serving and influencing Australia, Asia and the Pacific through advanced policy research, graduate and executive education, and policy impact. 


\title{
Oil Prices and the Global Economy: Is It Different This Time Around?*
}

\author{
Kamiar Mohaddes ${ }^{\text {ab }}$ and M. Hashem Pesaran ${ }^{\mathrm{c}}$ \\ ${ }^{a}$ Faculty of Economics and Girton College, University of Cambridge, UK \\ b Centre for Applied Macroeconomic Analysis, ANU, Australia \\ ${ }^{\mathrm{c}}$ Department of Economics \& USC Dornsife INET, University of Southern California, USA \\ and Trinity College, Cambridge, UK
}

July 3, 2016

\begin{abstract}
The recent plunge in oil prices has brought into question the generally accepted view that lower oil prices are good for the US and the global economy. In this paper, using a quarterly multi-country econometric model, we first show that a fall in oil prices tends relatively quickly to lower interest rates and inflation in most countries, and increase global real equity prices. The effects on real output are positive, although they take longer to materialize (around 4 quarters after the shock). We then reexamine the effects of low oil prices on the US economy over different sub-periods using monthly observations on real oil prices, real equity prices and real dividends. We confirm the perverse positive relationship between oil and equity prices over the period since the 2008 financial crisis highlighted in the recent literature, but show that this relationship has been unstable when considered over the longer time period of 1946-2016. In contrast, we find a stable negative relationship between oil prices and real dividends which we argue is a better proxy for economic activity (as compared to equity prices). On the supply side, the effects of lower oil prices differ widely across the different oil producers, and could be perverse initially, as some of the major oil producers try to compensate their loss of revenues by raising production. Taking demand and supply adjustments to oil price changes as a whole, we conclude that oil markets equilibrate but rather slowly, with large episodic swings between low and high oil prices.
\end{abstract}

JEL Classifications: C32, E17, E32, F44, F47, O51, Q43.

Keywords: Oil prices, equity prices, dividends, economic growth, oil supply, global oil markets, and international business cycle.

*Earlier versions of this paper have been presented at the University of Economics, Prague (May 20, 2016), the IIEA Fourth International Conference on Iran's Economy, Philipps-University of Marburg (June 17-18, 2016), and at the Third Annual Conference of the International Association for Applied Econometrics, University of Milano-Bicocca (June 22-25, 2016). We are grateful to Mehdi Raissi and Ron Smith for constructive comments and suggestions.

${ }^{\dagger}$ Corresponding author. Email address: km418@cam.ac.uk. 


\section{Introduction}

Oil markets have experienced frequent episodes of boom and bust, ever since oil was produced in large commercial quantities in Pennsylvania back in 1859. Real oil prices (WTI in 2015 US dollar) have fluctuated between highs of $\$ 145$ to lows of $\$ 15$ per barrel over the period 1946M1 and 2016M6 (Figure 1). The control of oil markets by the major international oil companies, the so called Seven Sisters, backed by the UK and US governments, meant low and relatively steady oil prices until the late 1960s. However, a new era began with the foundation of OPEC in 1960, the 1968 coup in Libya which led to new agreements initially with the independent oil companies and then with the Seven Sisters across all major oil producers in the Middle East and elsewhere, not to mention the start of a downward trend in US oil production in 1971. As a result, oil markets entered a new phase as the Seven Sisters lost control to markets and oil producers, oil prices quadrupled, ushering in an era of high oil price volatility and frequent periods of boom and bust often triggered by military and political events.

\section{Figure 1: Nominal and Real (2015 US dollars) WTI Oil Prices}

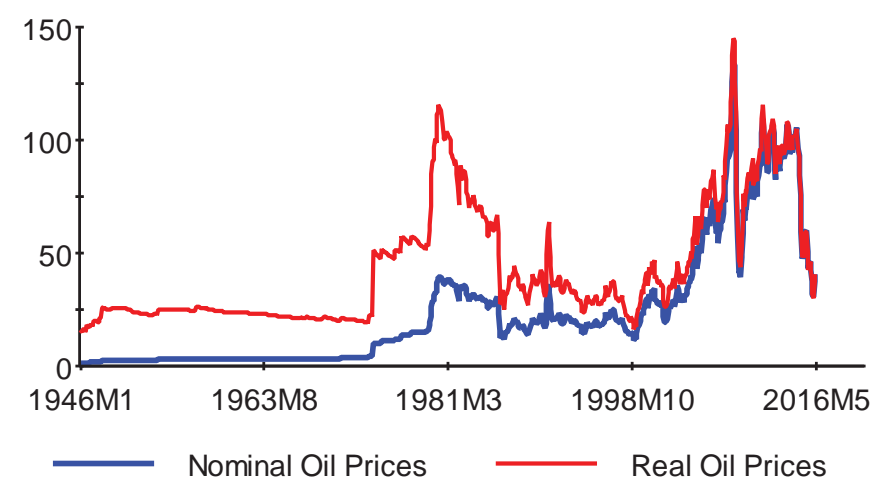

Data sources: United States Energy Information Administration (EIA).

In fact, since 1986 there have been six episodes of sharp decline in oil prices (30\% or more in each episode), in a relatively short period of time (within seven months), and with relatively large effects on the global economy (see Figure 1 and Baffes et al. 2015). Therefore, while the fall in oil prices since June 2014 is large, it is by no means unprecedented, and there is an extensive literature on the economic consequences of oil shocks for the global economy in terms of their impacts on real output and real equity prices, see for instance, Hamilton (2009), Kilian (2009), Cashin et al. (2014), Mohaddes and Pesaran (2015), and Mohaddes 
and Raissi (2015) among others. Overall the literature suggests that the initial impacts of oil price changes differ widely across different countries, with oil importers benefiting from the fall in oil prices (once demand conditions are controlled for) and oil exports losing from the price fall.

The recent plunge in oil prices has, however, brought into question the generally accepted view that lower oil prices are good for the US and the global economy. It has been argued that near-zero interest rates in most industrialized economies, and the fact that the US has started to export crude oil again, have altered the traditional channels through which the benefit of lower oil prices gets transmitted to the real economy (Obstfeld et al. 2016). Moreover, it has been suggested that the positive correlation between oil prices and equity markets in the past few years provides evidence of a slowdown in global economic activity, as a softening of global aggregate demand has reduced firms' profits and demand for oil (Bernanke 2016). Therefore, it is argued that the decline in oil prices this time around is not good news for the US economy, and by implication for the rest of the industrialized global economy.

But the net overall outcome for the global economy is far more complicated and depends on domestic political economy considerations and the feedback effects of oil price changes on global energy demand, interest rates, financial markets and world trade. Given that there are many channels through which oil prices can affect economic activity (both real and financial) in the US and elsewhere, one could for instance use the Global Vector Autoregressive (GVAR) modelling approach to capture the complicated patterns of global economic interactions; taking into account not only the direct exposure of countries to the shocks but also the indirect effects through secondary or tertiary channels. The GVAR is a multi-country framework which links country-specific models in a coherent manner using time series and panel data techniques and has been used in bank stress testing, the analysis of China's emergence on the rest of world economy, international transmission of real and financial shocks, and forecasting (see, for instance, Chudik and Pesaran 2016). To this end, we use the GVAR-Oil model developed in Mohaddes and Pesaran (2015), estimated using quarterly data between 1979Q2 and 2013Q1, and investigate the effects that a negative short-term oil price fall has on the US and the rest of the world economy. ${ }^{1}$ We find that the fall in oil prices tends to

\footnotetext{
${ }^{1}$ It is worth noting that much of the literature on oil and the macroeconomy does not use a multi-country framework, and instead uses a single-country VAR model, as representing the global economy. The majority of such studies in fact consider the effects of oil shocks exclusively on the United States, with the analysis being done mainly in isolation from the rest of the world. See, for instance, Kilian (2009). Unfortunately, these single-country models not only fail to take account of economic interlinkages and spillovers that exist between different regions, but more importantly their single-country framework does not allow them to consider heterogeneities across and within oil importers and exporters, which are arguably essential to analyzing the global oil market.
} 
lower interest rates and inflation in most countries, and increase global real equity prices, with these effects showing up relatively quickly, typically within two quarters. However, the positive real output effects, both at the global level and at the country levels, take longer to materialize following an oil price fall, with the positive median impulse responses generally manifesting themselves in the medium-term, around four quarters after a negative oil price shock.

To evaluate the effects of recent falls in oil prices, we need to investigate the output-oil price relationship over a number of sub-periods, including the episode of oil boom and bust since 2008. Unfortunately, however, quarterly macro series that exist are not sufficiently long for a reliable analysis of output-oil price relationship over different sub-periods, particularly the post-2008 crisis period. We cannot therefore make use of the GVAR-Oil model, but instead we consider bivariate relationships between oil prices, equity prices and dividends (as a proxy for real economic activity). Using monthly data from the US, we illustrate that there is no stable relationship between real oil prices and equity returns over the last 71 years and so the perverse response of equity markets to oil price changes should not be taken as evidence that lower oil prices are no longer beneficial for the US and the world economy. In fact, using relatively long time series on dividends and oil prices we show that, as in previous episodes of falling oil prices, lower oil prices improve profit opportunities and dividends in the oil importing economies which is overall good for the world economy. This supports the findings from the GVAR-Oil model. However, due to uncertainties over Brexit, the US elections, the threat of terrorism, and the surge in financial market volatility (to mention but a few), it is likely that there will be a delay in the materialization of any economic benefits of lower oil prices.

The remainder of this paper is organized as follows. Section 2 outlines a multi-country approach to examine the effects of lower oil prices, namely the GVAR-Oil model, and investigates the global macroeconomic consequences of a fall in oil prices using quarterly data between 1979Q2 and 2013Q1. Section 3 re-examines the effects of low oil prices on the US economy, particularly over the post-2008 period, using monthly regression analysis based on data on oil prices and indicators of market (S\&P 500) and real economic activity (proxied by dividends on the S\&P 500) over the 1946-2016 period. Section 4 argues that the response of oil producers (OPEC and non-OPEC) to price changes this time around differs markedly, mainly due to the US oil supply revolution and, finally, Section 5 offers some concluding remarks. 


\section{Analyzing the oil market using a multi-country model}

To analyze the international macroeconomic transmission of oil price shocks, we make use of the global econometric model developed in Mohaddes and Pesaran (2015). Their approach is particularly relevant as, in contrast to most of the literature, they model global oil markets separately from the country-specific vector autoregressive models conditional on foreign variables (known as VARX* models), by specifying an oil price equation which takes account of global demand conditions as well as oil supply conditions across some of the major oil producing countries. They then integrate the oil market within a compact quarterly model of the global economy comprising 27 countries (see Table 1), with the euro area being treated as a single economy, using a dynamic multi-country framework first advanced by Pesaran et al. (2004), known as the Global VAR (or GVAR for short). This approach allows for an analysis of the international macroeconomic transmission of the effects of country-specific shocks, taking into account not only the direct exposure of countries to the shocks but also the indirect effects through secondary and tertiary channels.

Table 1: Countries and Regions in the GVAR-Oil Model

\begin{tabular}{|c|c|c|c|}
\hline Major Oil Producers & \multicolumn{3}{|c|}{ Other Countries } \\
\hline Net Exporters & Europe & Asia Pacific & Latin America \\
\hline Canada & Euro Area & Australia & Argentina \\
\hline Indonesia & Austria & India & Chile \\
\hline Iran & Belgium & Japan & Peru \\
\hline Mexico & Finland & Korea & \\
\hline Norway & France & Malaysia & \\
\hline Saudi Arabia & $\begin{array}{l}\text { Germany } \\
\text { Italy }\end{array}$ & $\begin{array}{l}\text { New Zealand } \\
\text { Philippines }\end{array}$ & $\begin{array}{l}\text { Rest of the World } \\
\text { South Africa }\end{array}$ \\
\hline Net Importers & Netherlands & Singapore & Turkey \\
\hline Brazil & Spain & Thailand & \\
\hline China & Sweden & & \\
\hline United Kingdom & Switzerland & & \\
\hline United States & & & \\
\hline
\end{tabular}

The individual country-specific models are solved in a global setting where core macroeconomic variables of each economy (real GDP, inflation, real exchange rate, short and long-term interest rates, and oil production) are related to corresponding foreign variables, (also known as "star" variables) constructed to match the international trade pattern of the country under consideration. Star variables serve as proxies for common unobserved factors and affect the global economy in addition to the set of common observable variables (oil prices and global equity prices). They estimate the 27 country-specific VARX* models over 
the period 1979Q2 to 2013Q1 separately and then combine these with the estimates from the global oil market, which they refer to as the GVAR-Oil model.

There are many advantages to using a multi-country framework, like that of the GVAROil model. Firstly, the disaggregated nature of the GVAR-Oil model allows one to identify country-specific shocks and answer counterfactual questions regarding the possible macroeconomic effects of oil supply disruptions in specific geographical areas on the global economy. This is in contrast to most of the literature that focuses on the identification of global supply shocks, rather than shocks to a specific country or region. Secondly, it allows one to deal with inherent heterogeneities that exist across countries, not only at the geopolitical level but also in terms of oil reserves and production capacities, to mention but a few. ${ }^{2}$ Thirdly, this compact model of the world economy allows one to take into account the economic interlinkages and spillovers that exist between different regions, thereby enabling a study of the global economy in a coherent manner as opposed to undertaking country-by-country analysis. In this paper we use this multi-country model to investigate the effects of a fall in oil prices on the global economy, both at the country and the aggregate level. But before describing our results, we provide a short exposition of the GVAR-Oil model below.

\subsection{The GVAR-Oil model}

To simplify the exposition we consider the simple dynamic oil price equation (here we set all lag orders to unity, but consider more general dynamics in the empirical application)

$$
\tilde{p}_{t}^{o}=c_{p}+\phi_{1} \tilde{p}_{t-1}^{o}+\alpha_{1} y_{t-1}+\beta_{1} q_{t-1}^{o}+u_{t}^{o}
$$

where

$$
y_{t}=\sum_{i=1}^{N} w_{i} y_{i t}, \text { and } q_{t}^{o}=\sum_{i=1}^{N} w_{i}^{o} q_{i t}^{o},
$$

$y_{i t}$ and $q_{i t}^{o}$ are the real income and quantity of oil output of country $i$ at time $t$, respectively, $w_{i}$ and $w_{i}^{o}$ are the weights attached to country $i^{\prime} s$ real income and oil production in the construction of the world GDP $\left(y_{t}\right)$ and oil supply $\left(q_{t}^{o}\right), \tilde{p}_{t}^{o}$ is the weighted average of countryspecific log real oil prices, defined by

$$
\tilde{p}_{t}^{o}=\sum_{i=1}^{N} \omega_{i} \tilde{p}_{i t}^{o}
$$

\footnotetext{
${ }^{2}$ For instance, the BP Statistical Review of World Energy (June 2016) reports that $14 \%$ of the total proven oil reserves in the world is located in North America, while more than $47 \%$ is located in the Middle East, with significant heterogeneity of production costs between the two regions.
} 


$$
\tilde{p}_{i t}^{o}=\ln \left(P_{t}^{o} E_{i t} / P_{i t}\right)=p_{t}^{o}+\left(e_{i t}-p_{i t}\right),
$$

$P_{t}^{o}$ is the nominal price of oil in US dollar, $E_{i t}$ is country $i^{t h}$ exchange rate measured by the units of country $i^{\text {th }}$ currency in one US dollar, and $P_{i t}$ is the general level of prices in country $i . u_{t}^{o}$ represents the global oil demand shock to be distinguished from countryspecific oil supply shocks defined in the country-specific models (specified below). The above decomposition of country-specific real oil prices into the US dollar price component and the "real" exchange rate component (here defined by $e p_{i t}=e_{i t}-p_{i t}$ ) is important, since only the US dollar oil price component, $p_{t}^{o}$, can be regarded as weakly exogenous. The real exchange rate component, $e p_{i t}$, is determined endogenously with the other variables in the countryspecific models, such as interest rates and real output.

In order to integrate the oil price equation within a multi-country set-up we need to write the oil price equation in terms of $p_{t}^{o}$. To this end using (4) in (3) we first note that $\tilde{p}_{t}^{o}=p_{t}^{o}+e p_{t}$, where $^{3}$

$$
e p_{t}=\sum_{i=1}^{N} \omega_{i} e p_{i t} .
$$

Using this result the oil price equation can be written as

$$
p_{t}^{o}+e p_{t}=c_{p}+\phi_{1}\left(p_{t-1}^{o}+e p_{t-1}\right)+\alpha_{1} y_{t-1}+\beta_{1} q_{t-1}^{o}+u_{t}^{o} .
$$

In the GVAR set-up, the country-specific variables, $e p_{i t}, y_{i t}$ and $q_{i t}^{o}$, are determined jointly with the other macro variables. Specifically, we consider the following country-specific models (for $i=1,2, \ldots, N)$

$$
\mathbf{x}_{i t}=\mathbf{a}_{i 0}+\mathbf{a}_{i 1} t+\boldsymbol{\Phi}_{i} \mathbf{x}_{i, t-1}+\boldsymbol{\Lambda}_{i 0} \mathbf{x}_{i t}^{*}+\boldsymbol{\Lambda}_{i 1} \mathbf{x}_{i, t-1}^{*}+\Upsilon_{i 0} p_{t}^{o}+\mathbf{\Upsilon}_{i 1} p_{t-1}^{o}+\mathbf{u}_{i t},
$$

where $\mathbf{a}_{i 0}, \mathbf{a}_{i 1}, \boldsymbol{\Phi}_{i}, \boldsymbol{\Lambda}_{i 0}, \boldsymbol{\Lambda}_{i 1}, \boldsymbol{\Upsilon}_{i 0}$, and $\boldsymbol{\Upsilon}_{i 1}$ are vectors/matrices of fixed coefficients that vary across countries, $\mathbf{x}_{i t}$ is $k_{i} \times 1$ vector of country-specific endogenous variables that include $e p_{i t}, y_{i t}$, and $q_{i t}^{o}$ (as applicable), and $\mathbf{x}_{i t}^{*}$ is $k_{i}^{*} \times 1$ vector of country-specific weakly exogenous (or 'star' variables). The 'star' variables, $\mathbf{x}_{i t}^{*}$, are constructed using country-specific trade shares, and defined by

$$
\mathbf{x}_{i t}^{*}=\sum_{j=1}^{N} w_{i j} \mathbf{x}_{j t},
$$

\footnotetext{
${ }^{3}$ In the literature, the real oil price is typically computed by deflating the nominal oil price with the US general price index. But as our analysis shows, for global analysis such a procedure is not valid unless the law of one price holds universally, namely if $E_{i t} P_{U S, t}=P_{i t}$ for all $i$. Only under such stringent conditions it follows that $\tilde{p}_{t}^{o}=p_{t}^{o}+\sum_{i=1}^{N} \omega_{i} \ln \left(E_{i t} / P_{i t}\right)=p_{t}^{o}+\sum_{i=1}^{N} \omega_{i} \ln \left(1 / P_{U S, t}\right)=p_{t}^{o}-p_{U S, t}$.
} 
where $w_{i j}, i, j=1,2, \ldots N$, are bilateral trade weights, with $w_{i i}=0$, and $\sum_{j=1}^{N} w_{i j}=1$.

In our application each country-specific model has a maximum of six endogenous variables. Using the same terminology as in equation (7), the $k_{i} \times 1$ vector of country-specific endogenous variables is defined as $\mathbf{x}_{i t}=\left(q_{i t}^{o}, y_{i t}, \pi_{i t}, e p_{i t}, r_{i t}^{S}, r_{i t}^{L},\right)^{\prime}$, where $q_{i t}^{o}$ is the $\log$ of oil production at time $t$ for country $i, y_{i t}$ is the log of real Gross Domestic Product, $\pi_{i t}$ is the rate of inflation, $e p_{i t}$ is the log deflated exchange rate, and $r_{i t}^{S}\left(r_{i t}^{L}\right)$ is the short (long) term interest rate, if country $i$ is a major oil producer, otherwise $\mathbf{x}_{i t}=\left(y_{i t}, \pi_{i t}, e p_{i t}, r_{i t}^{S}, r_{i t}^{L},\right)^{\prime} .{ }^{4}$ The model for the US differs from the rest in two respects: given the importance of US financial variables in the global economy, the log of world real equity prices, $e q_{t}$, is included in the US model as an endogenous variable, and as weakly exogenous in the other country models $\left(e q_{i t}^{*}=e q_{t}\right)$, whilst US dollar exchange rates are included as endogenous variables in all models except for the United States. The endogenous variables of the US model are therefore given by $\mathbf{x}_{U S, t}=\left(e q_{t}, q_{U S, t}^{o}, y_{U S, t}, \pi_{U S, t}, r_{U S, t}^{S}, r_{U S, t}^{L}\right)^{\prime}$.

In the case of all countries, except for the US and the euro area, the foreign variables included in the country-specific models, computed as in equation (8), are given by $\mathbf{x}_{i t}^{*}=$ $\left(e q_{i t}^{*}, y_{i t}^{*}, \pi_{i t}^{*}, e p_{i t}^{*}, r_{i t}^{* S}, r_{i t}^{* L}\right)^{\prime}$. The trade weights are computed as three-year averages over $2007-2009 .{ }^{5}$ We excluded the foreign inflation variable, $\pi_{E A, t}^{*}$, from the euro model since, based on some preliminary tests, we could not maintain that $\pi_{E A, t}^{*}$ is weakly exogenous. Also, given the pivotal role played by the US in global financial markets, we excluded the foreign interest rates, $r_{U S, t}^{* S}$ and $r_{U S, t}^{* L}$, from the US model. The exclusion of these variables from the US model was also supported by preliminary test results showing that $r_{U S, t}^{* S}$ and $r_{U S, t}^{* L}$ cannot be assumed to be weakly exogenous when included in the US model. A similar result was found when the foreign inflation variable, $\pi_{U S, t}^{*}$, was included in the US model. In short, the US model includes only two foreign variables, namely $\mathbf{x}_{U S, t}^{*}=\left(y_{U S, t}^{*}, e p_{U S, t}^{*}\right)^{\prime}$, where $e p_{U S, t}^{*}=\sum_{j=1}^{N} w_{U S A, j}\left(e_{j t}-p_{j t}\right), w_{U S A, j}$ is the share of US trade with country $j, e_{j t}$ is the log of US dollar exchange rate with respect to the currency of country $j$, and $p_{j t}$ is the $\log$ CPI price index of country $j$.

The country-specific VARX* models, (7), are combined with the oil price equation, (6), and solved for all the endogenous variables collected in the vector, $\mathbf{z}_{t}=\left(p_{t}^{o}, \mathbf{x}_{1 t}^{\prime}, \mathbf{x}_{2 t}^{\prime}, \ldots, \mathbf{x}_{N t}^{\prime}\right)^{\prime}=$ $\left(p_{t}^{o}, \mathbf{x}_{t}^{\prime}\right)^{\prime}$. We refer to this combined model as the GVAR-Oil model, which allows for a twoway linkage between the global economy and oil prices. Changes in the global economic conditions and oil supplies affect oil prices with a lag, with oil prices potentially influencing all country-specific variables. Similarly, changes in oil supplies, determined in country mod-

\footnotetext{
${ }^{4}$ Note that long-term interest rates are not available for all countries, and short-term and long-term interest rates are not available in the case of Iran and Saudi Arabia.

${ }^{5} \mathrm{~A}$ similar approach has also been followed in the case of Global VAR models estimated in the literature. See, for example, Dees et al. (2007) and Cashin et al. (2015, 2016).
} 
els for the major oil producers, are affected by oil prices and in turn affect oil prices with a lag as specified in the oil price equation, (6).

Although estimation is carried out on a country-by-country basis, the GVAR model is solved for oil prices and all country variables simultaneously, taking account of the fact that all variables are endogenous to the system as a whole. To solve for the endogenous variables, $\mathbf{z}_{t}$, using (8) we first note that $\mathbf{x}_{i t}^{*}=\mathbf{W}_{i} \mathbf{x}_{t}$, where $\mathbf{W}_{i}$ is a $k_{i}^{*} \times(k+1)$, matrix of fixed constants (which are either 0 or 1 or some pre-specified weights, $w_{i j}$ ), $k=\sum_{i=1}^{N} k_{i}$, $k_{i}^{*}=\operatorname{dim}\left(\mathbf{x}_{i t}^{*}\right)$. Stacking the country-specific models we now have

$$
\mathbf{x}_{t}=\boldsymbol{\varphi}_{t}+\boldsymbol{\Phi} \mathbf{x}_{t-1}+\mathbf{H}_{0} \mathbf{x}_{t}+\mathbf{H}_{1} \mathbf{x}_{t-1}+\Upsilon_{0} p_{t}^{o}+\Upsilon_{1} p_{t-1}^{o}+\mathbf{u}_{t}
$$

where

$$
\begin{gathered}
\boldsymbol{\Phi}=\left(\begin{array}{cccc}
\boldsymbol{\Phi}_{1} & \mathbf{0} & \cdots & \mathbf{0} \\
\mathbf{0} & \boldsymbol{\Phi}_{2} & \cdots & \mathbf{0} \\
\vdots & \vdots & \ddots & \vdots \\
\mathbf{0} & \mathbf{0} & \cdots & \boldsymbol{\Phi}_{N}
\end{array}\right), \mathbf{H}_{0}=\left(\begin{array}{c}
\boldsymbol{\Lambda}_{10} \mathbf{W}_{1} \\
\boldsymbol{\Lambda}_{20} \mathbf{W}_{2} \\
\vdots \\
\boldsymbol{\Lambda}_{N 0} \mathbf{W}_{N}
\end{array}\right), \mathbf{H}_{1}=\left(\begin{array}{c}
\boldsymbol{\Lambda}_{11} \mathbf{W}_{1} \\
\boldsymbol{\Lambda}_{21} \mathbf{W}_{2} \\
\vdots \\
\boldsymbol{\Lambda}_{N 1} \mathbf{W}_{N}
\end{array}\right), \\
\boldsymbol{\varphi}_{t}=\left(\begin{array}{c}
\mathbf{a}_{10}+\mathbf{a}_{11} t \\
\mathbf{a}_{20}+\mathbf{a}_{21} t \\
\vdots \\
\mathbf{a}_{N 0}+\mathbf{a}_{N 1} t
\end{array}\right), \boldsymbol{\Upsilon}_{0}=\left(\begin{array}{c}
\boldsymbol{\Upsilon}_{10} \\
\boldsymbol{\Upsilon}_{20} \\
\vdots \\
\mathbf{\Upsilon}_{N 0}
\end{array}\right), \boldsymbol{\Upsilon}_{1}=\left(\begin{array}{c}
\mathbf{\Upsilon}_{11} \\
\boldsymbol{\Upsilon}_{21} \\
\vdots \\
\mathbf{\Upsilon}_{N 1}
\end{array}\right), \mathbf{u}_{t}=\left(\begin{array}{c}
\mathbf{u}_{1 t} \\
\mathbf{u}_{2 t} \\
\vdots \\
\mathbf{u}_{N t}
\end{array}\right)
\end{gathered}
$$

We also note that the oil price equation (6) can be written as

$$
p_{t}^{o}+\mathbf{w}_{e p}^{\prime} \mathbf{x}_{t}=c_{p}+\phi_{1}\left(p_{t-1}^{o}+\mathbf{w}_{e p}^{\prime} \mathbf{x}_{t-1}\right)+\left(\alpha_{1} \mathbf{w}_{y}^{\prime}+\beta_{1} \mathbf{w}_{q}^{\prime}\right) \mathbf{x}_{t-1}+u_{t}^{o},
$$

where $\mathbf{w}_{e p}, \mathbf{w}_{y}$ and $\mathbf{w}_{q}$ are $k \times 1$ vectors whose elements are either zero or are set equal to the weights $w_{i}$ or $w_{i}^{0}$, assigned to $e p_{i t}, y_{i t}$ or $q_{i t}^{o}$, as implied by (5) and (2), respectively. Combining the above oil price equation with the country-specific models we obtain

$$
\left(\begin{array}{cc}
1 & \mathbf{w}_{e p}^{\prime} \\
-\mathbf{\Upsilon}_{0} & \mathbf{I}_{k}-\mathbf{H}_{0}
\end{array}\right)\left(\begin{array}{c}
p_{t}^{o} \\
\mathbf{x}_{t}
\end{array}\right)=\left(\begin{array}{c}
c_{p} \\
\boldsymbol{\varphi}_{t}
\end{array}\right)+\left(\begin{array}{cc}
\phi_{1} & \phi_{1} \mathbf{w}_{e p}^{\prime}+\alpha_{1} \mathbf{w}_{y}^{\prime}+\beta_{1} \mathbf{w}_{q}^{\prime} \\
\mathbf{\Upsilon}_{1} & \mathbf{\Phi}+\mathbf{H}_{1}
\end{array}\right)\left(\begin{array}{c}
p_{t-1}^{o} \\
\mathbf{x}_{t-1}
\end{array}\right)+\left(\begin{array}{c}
u_{t}^{o} \\
\mathbf{u}_{t}
\end{array}\right)
$$

which can be written more compactly as

$$
\mathbf{G}_{0} \mathbf{z}_{t}=\mathbf{b}_{t}+\mathbf{G}_{1} \mathbf{z}_{t-1}+\mathbf{v}_{t}
$$


Under the assumption that $\mathbf{I}_{k}-\mathbf{H}_{0}$ is invertible the GVAR-Oil model has the following reduced form solution

$$
\mathbf{z}_{t}=\mathbf{a}_{t}+\mathbf{F} \mathbf{z}_{t-1}+\boldsymbol{\xi}_{t},
$$

where $\mathbf{a}_{t}=\mathbf{G}_{0}^{-1} \mathbf{b}_{t}$ and $\mathbf{F}=\mathbf{G}_{0}^{-1} \mathbf{G}_{1}, \boldsymbol{\xi}_{t}=\mathbf{G}_{0}^{-1} \mathbf{v}_{t}$.

\subsection{Effects of a fall in oil prices}

We use the GVAR-Oil model to examine the direct and indirect effects of negative oil price shocks on the world economy, on a country-by-country basis, and provide the time profile of the effects on real outputs across countries, interest rates, inflation and real global equity prices. As explained earlier, the modelling approach is based on that in Mohaddes and Pesaran (2015), we therefore do not present the country-specific estimates and the associated diagnostic tests here, but refer the reader to Mohaddes and Pesaran (2015). ${ }^{6}$

Figure 2 displays the plots of generalized impulse responses for the effects of a negative short-term oil price shock on global real equity prices, long-term interest rates, as well as real output (based on PPP-GDP weighted responses of the 27 countries in our sample). It can be seen that negative oil price changes tend to increase real equity prices and reduce interest rates. The same pattern is also evident when considering the country-by-country impulse responses. In particular Figure 3 illustrates the fall in long-term interest rates across the major economies in the world following an oil price decline. ${ }^{7}$ We also find strong disinflation pressures in all major (net) oil importers, see Figure 4. These results are as expected, and are in line with those reported in the literature. See, for instance, Dees et al. (2007).

While the responses of global equity prices, long-term interest rates and inflation show up relatively quickly and within a few quarters, the effects of oil price changes on real output, both at country levels and globally, take longer to manifest themselves. More specifically, the impulse responses for global GDP following an oil price fall is positive in the medium-term (Figure 2), which is also the case for the individual country responses in Figure 5. Thus the empirical evidence based on the GVAR-Oil model supports the view that an oil price fall is good news for the US, the other major economies, as well as for the global economy.

\footnotetext{
${ }^{6}$ In particular, see Section 4.1 of Mohaddes and Pesaran (2015) for the estimates of the oil price equation and Section 4.2 for estimates of the country-specific VARX* models including discussions about lag order selection, cointegrating relations, and persistence profiles. Evidence for the weak exogeneity assumption of the foreign variables and discussion of the issue of structural breaks in the context of the GVAR-Oil model is given in Appendix B. Finally, for various data sources used to build the quarterly dataset, covering 1979Q2 to 2013Q1, and for the construction of the variables see Appendix A of Mohaddes and Pesaran (2015).

${ }^{7}$ The results for the other countries in our sample, listed in Table 1, are not reported here, but are available on request.
} 
Figure 2: Effects of Lower Oil Prices on Global Real Equity Prices, Long-Term Interest Rates, and Real GDP

Global Real Equity Prices

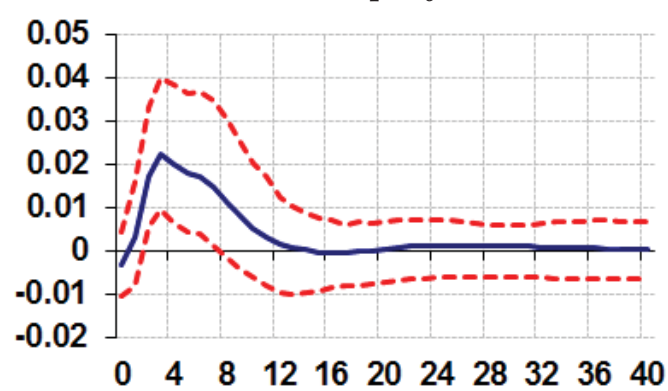

Global Real GDP

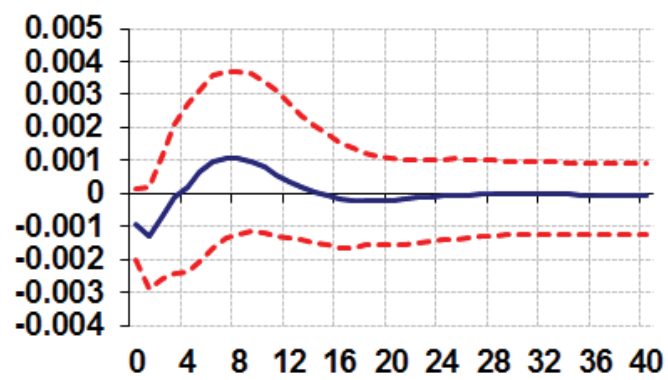

Global Long-Term Interest Rates

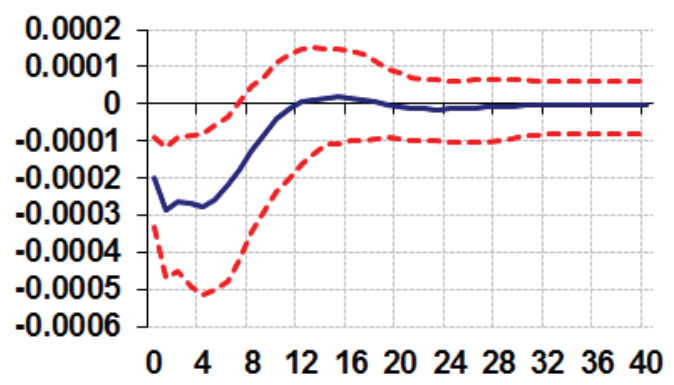

Oil Prices

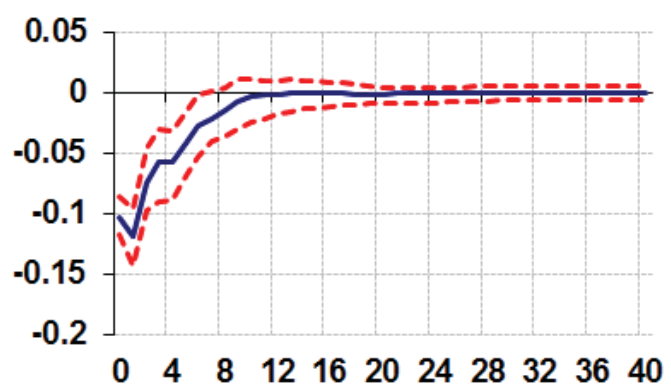

Notes: Figures show median impulse responses to a one-standard-deviation decrease in oil prices, with 95 percent bootstrapped confidence bounds. The horizon is quarterly. 
Figure 3: Effects of Lower Oil Prices on Long-Term Interest Rates in Various Countries

United States

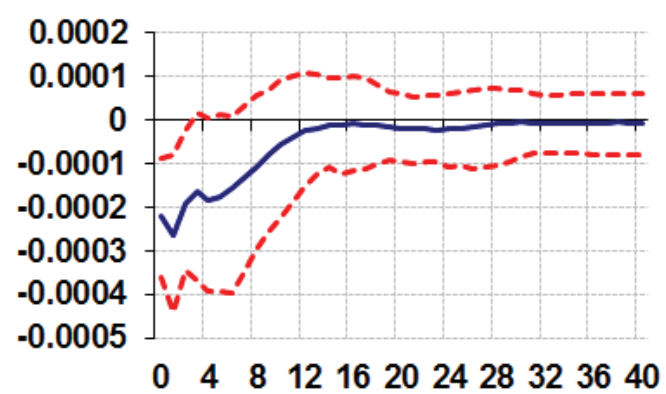

United Kingdom

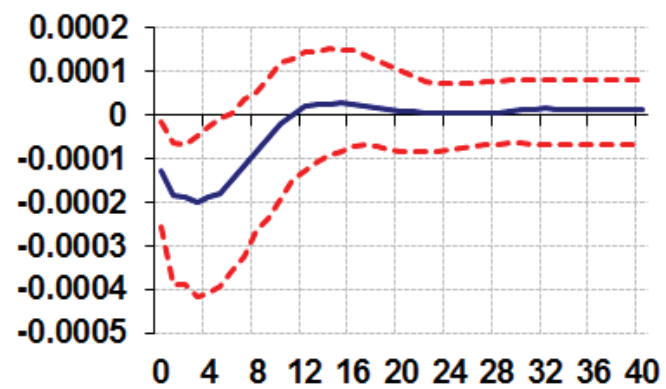

Euro Area

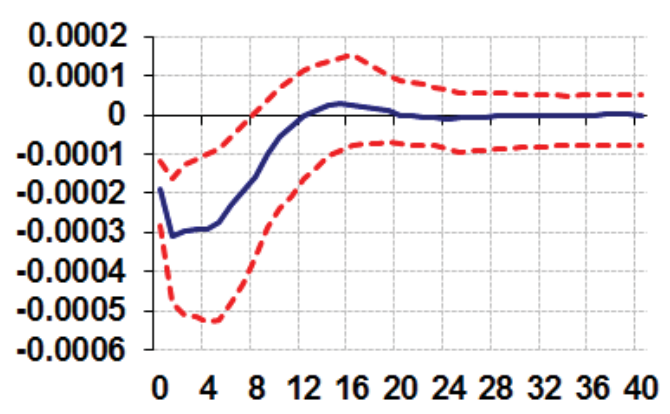

Japan

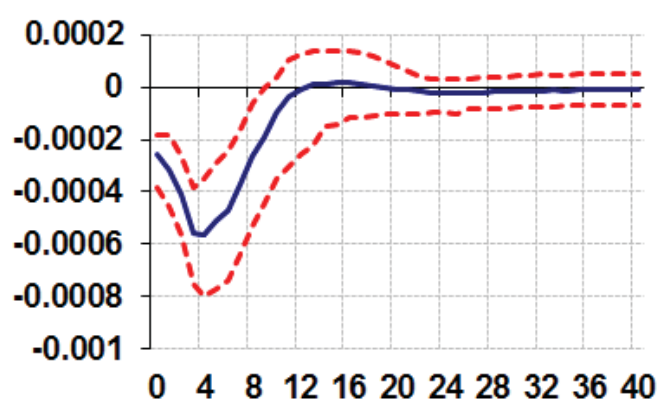

Notes: Figures show median impulse responses to a one-standard-deviation decrease in oil prices, with 95 percent bootstrapped confidence bounds. The horizon is quarterly. 
Figure 4: Effects of Lower Oil Prices on Inflation in Various Countries

United States

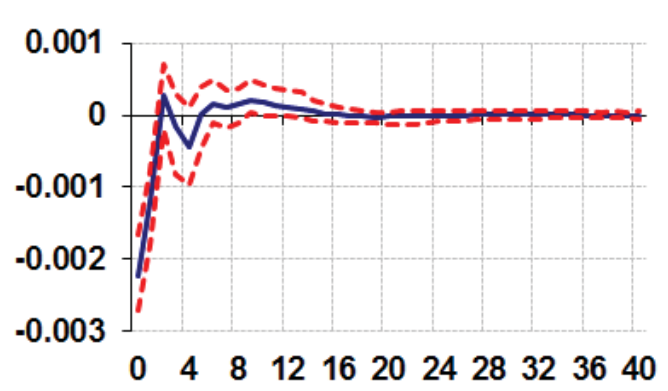

United Kingdom

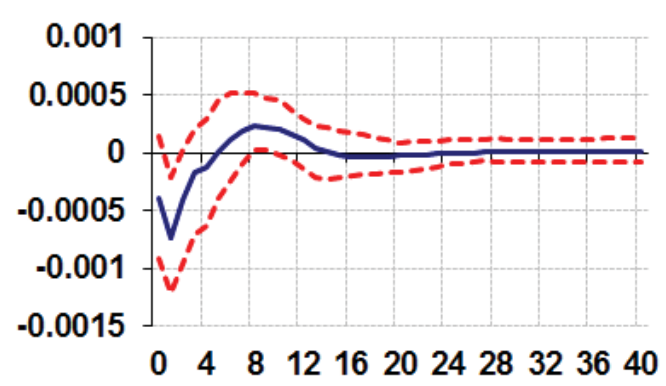

China

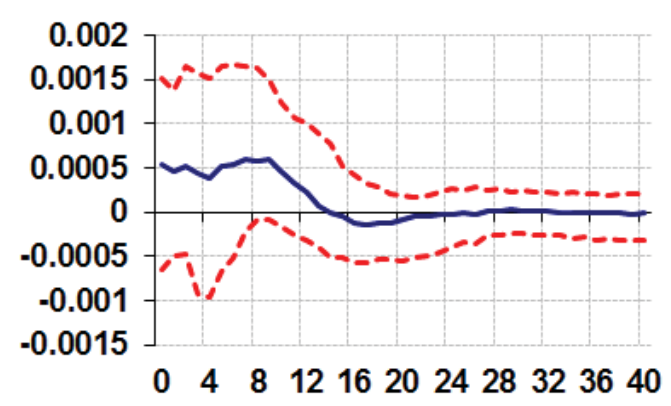

Euro Area

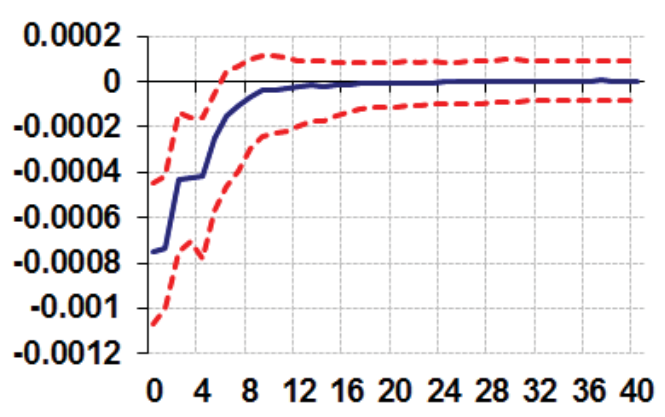

Japan

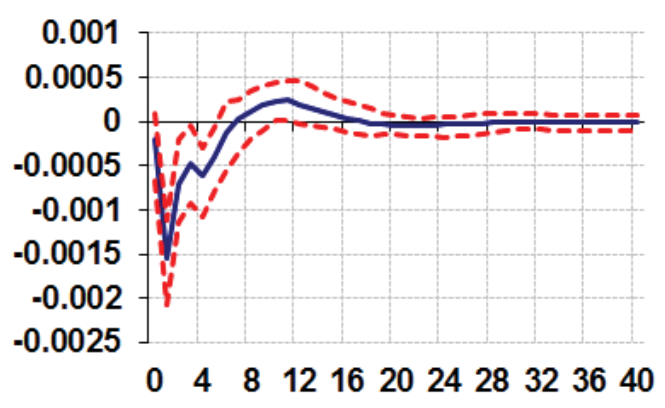

Notes: Figures show median impulse responses to a one-standard-deviation decrease in oil prices, with 95 percent bootstrapped confidence bounds. The horizon is quarterly. 
Figure 5: Effects of Lower Oil Prices on Real GDP in Various Countries

United States

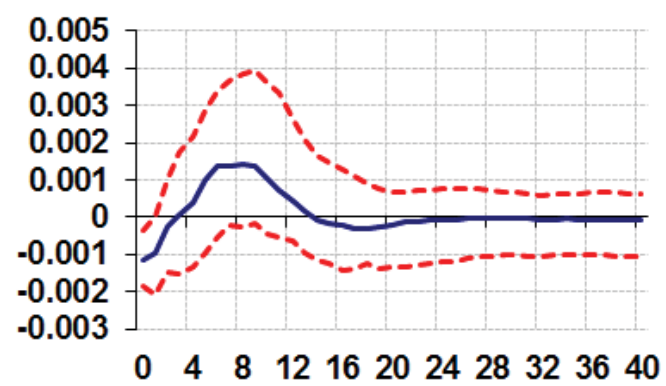

United Kingdom

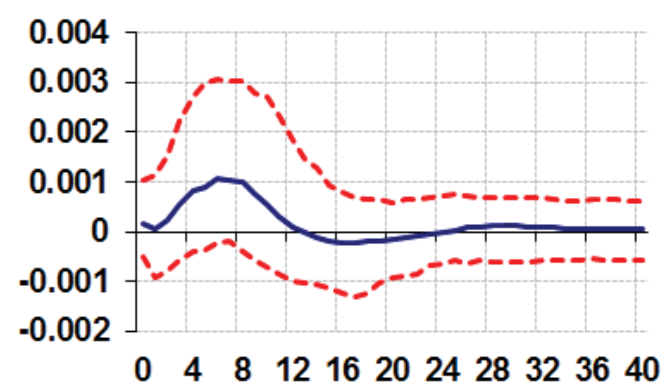

China

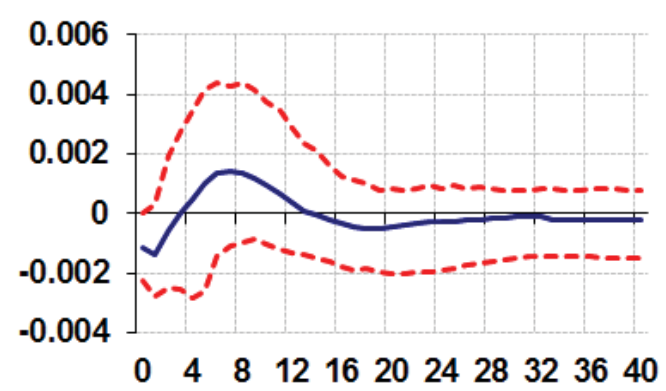

Euro Area

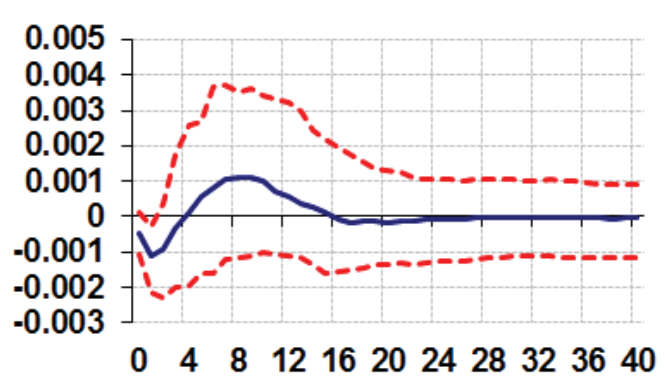

Japan

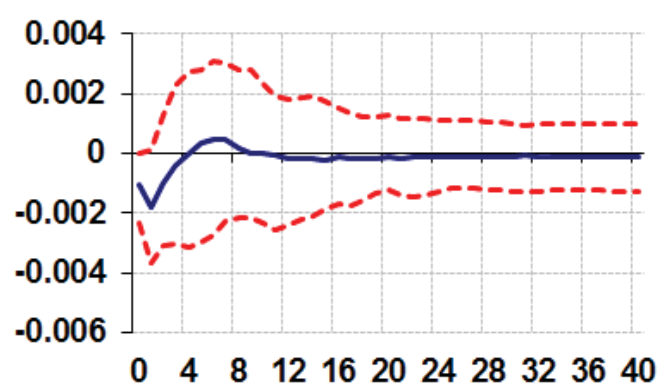

Notes: Figures show median impulse responses to a one-standard-deviation decrease in oil prices, with 95 percent bootstrapped confidence bounds. The horizon is quarterly. 


\section{Analyzing oil price changes using monthly data}

In what follows we shall mainly focus on the effects of lower oil prices on the US economy for three reasons. Firstly, the US economy has not been dependent on oil imports as much as other industrialized economies, with oil production having first peaked in 1971 (before the shale oil revolution). In fact, the US started to export crude oil in January 2016 after a 40-year ban. Secondly, thanks to advances in hydraulic fracturing and directional drilling, oil production has significantly expanded in the US over the past 10 years (see Figure 6). US oil production has risen from 5 million barrels per day (b/d) in January 2008 to 9.2 million b/d in January 2016, around $84 \%$ increase. Thirdly, the US oil and gas sector attracted significant investment over the past decade, including small firms issuing large amounts of debt (estimated over $\$ 350$ billion just between 2010 and 2014). As a result, the losses for US investors in equity and bond markets have been substantial following the recent fall in oil prices, with valuations of US energy companies falling dramatically and the number of gas and oil companies in the US filing for bankruptcy soaring, which could have indirect effects on the US economy through secondary or tertiary channels. It is, therefore, important to re-examine the effects of low oil prices on the US economy, particularly over the post-2008 period. To this end we examine the relationship between oil prices and indicators of market (S\&P 500) and real economic activity (proxied by dividends on the S\&P 500) using monthly data from 1946 to 2016.

Figure 6: US Oil Production (1000 barrels/day)

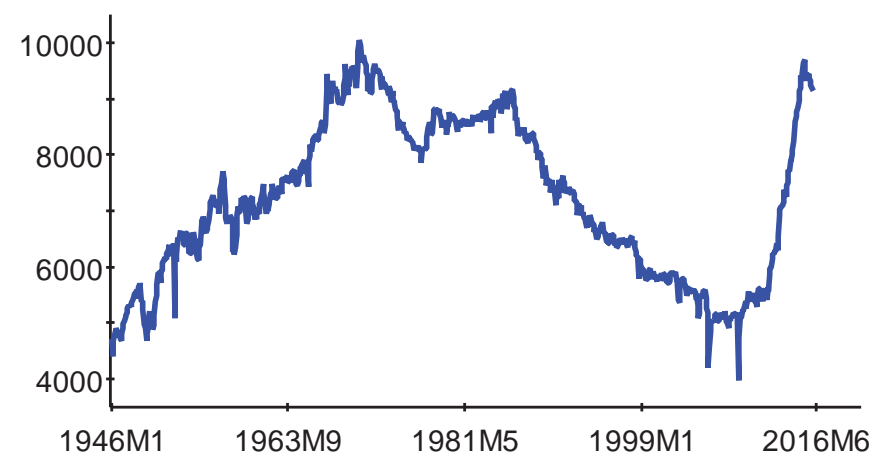

Data sources: United States Energy Information Administration (EIA). 


\subsection{Has the relationship between real oil and equity prices been stable over time?}

Figure 7 shows the monthly evolution of real oil prices, in 2015 US dollars per barrel, and US real equity prices, as measured by the S\&P 500 index, from which it is clear that taking a relatively long historical perspective (1946-2016), there seems little evidence of a stable relationship between oil prices and real equity prices. Moreover, Table 2 illustrates that there are sub-periods where changes in real oil prices and real equity prices are unrelated, as well as sub-periods over which they are negatively and positively correlated. However, over the full sample the simple correlation coefficient is not significant.

Figure 7: Real Oil Prices and Real US Equity Prices (S\&P 500), 1946M1-2016M3

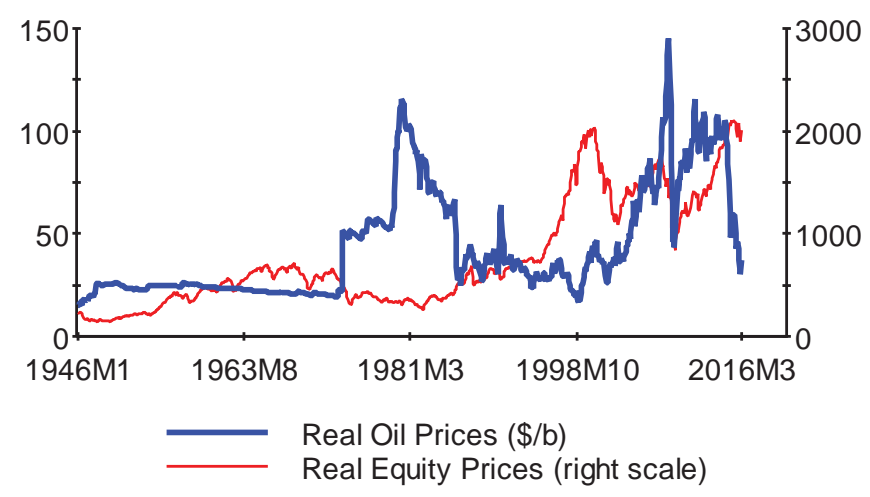

Data sources: Robert Shiller's online database, Federal Reserve Economic Data (FRED), and United States Energy Information Administration (EIA).

To conduct a more robust statistical analysis we use rolling regressions of the rate of change of real equity prices on the rate of change of real oil prices, estimated with 10-year windows, and then plot the coefficient of the rate of change of real oil prices (blue solid) and its two standard error bands (red dashed) in Figure 8. This figure shows that the coefficients were not statistically different from zero before 1990, became negative in 1991 and initially falling (being statistically significant from 1991 to 2001), and then eventually rising and becoming positive since the 2008 financial crisis (being statistically significant from 2012 onwards). It is then perhaps not surprising that there is no consensus in the literature on the relationship between oil and equity prices (Jones and Kaul 1996 and Wei 2003).

As Table 2 and Figure 7 show, a significantly positive relationship between oil and equity prices has emerged since the global financial crisis in 2008, which has been discussed exten- 
Table 2: Correlations between Changes in Real Oil Prices, Equity Prices and Dividends

\begin{tabular}{lcc}
\hline Period & $\begin{array}{c}\text { Real Oil and } \\
\text { Equity Prices }\end{array}$ & $\begin{array}{c}\text { Real Oil Prices } \\
\text { and Dividends }\end{array}$ \\
\hline Full Period & $0.008(0.035)$ & $\mathbf{- 0 . 1 0 5}(0.034)$ \\
1946M2-2016M3 & & \\
Sub-Periods & $0.018(0.063)$ & $-0.071(0.063)$ \\
1960M1-1980M12 & $\mathbf{- . 1 3 9}(0.064)$ & $\mathbf{- 0 . 1 6 3}(0.064)$ \\
1981M1-2000M12 & $\mathbf{0 . 1 9 9}(0.073)$ & $\mathbf{- 0 . 2 5 2}(0.072)$ \\
2001M1-2016M3 & & \\
& & \\
Sub-Sub-Periods & $-0.144(0.109)$ & $\mathbf{- 0 . 0 8 8}(0.110)$ \\
2001M1-2007M12 & $\mathbf{0 . 4 0 4}(0.093)$ & $\mathbf{- 0 . 3 2 9}(0.096)$ \\
2008M1-2016M3 & & \\
\hline
\end{tabular}

Notes: A bold correlation highlights significance, with standard errors in parentheses. Data sources: Robert Shiller's online database, Federal Reserve Economic Data (FRED), and United States Energy Information Administration (EIA).

Figure 8: Rolling Estimates of the Effects of Changes in Oil Prices on Equity Prices

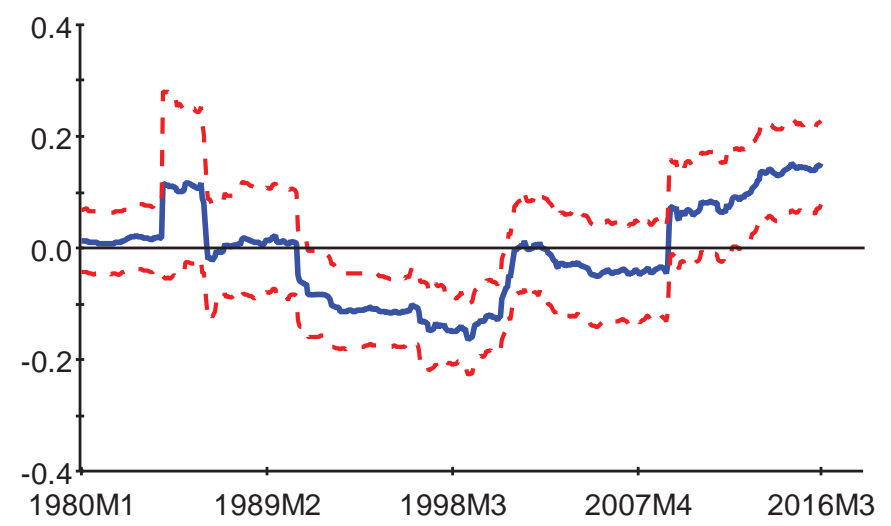

Notes: Rolling estimates of the coefficient of the rate of change of real oil prices and its two standard error bands. Dependant variable is the rate of change of real US equity prices (S\&P 500). The window size is 120 months.

Data sources: Robert Shiller's online database, Federal Reserve Economic Data (FRED), and United States Energy Information Administration (EIA). 
sively by the media as well as by prominent economists (see Bernanke's blog at Brookings on February 2016 and Obstfeld et al.'s IMF blog on March 2016) over the last few months. The question is why is this the case? There could be a number of reasons. Firstly, while markets are generally efficient and therefore equity prices reflect the fundamentals, there are also episodes when real equity prices do not reflect the state of the economy. In such periods any evidence of a perverse relationship between real equity and oil prices could be due to the disconnect between equity markets and economic fundamentals and not necessarily any breaks in the relationship between oil prices and the real economy. Secondly, Sovereign Wealth Funds (SWFs) accumulated large assets during the most recent oil boom (2002-2008) and they have come to play a major role in reserve management of oil revenues. The prominent examples are Norway's Government Pension Fund (\$830), Abu Dhabi Investment Authority (\$773), Saudi Arabia's Fund (SAMA) (\$685), Kuwait Investment Authority (\$592), and Qatar Investment Authority (\$256), with the number in brackets referring to their market values in billions in June 2015. On average $65 \%$ of SWF assets are held in public and private equities (61\% Norway; 72\% SAMA; 65\% Kuwait; $68 \%$ Qatar; $62 \%$ Abu Dhabi-figures based on 2014). During periods of rising oil prices, these funds are topped up with equity purchases. However, when oil prices are falling most major oil exporters withdraw money from the funds in order to maintain, for instance, their welfare expenditure. The equity transactions of SWFs in turn induce an unintended positive correlation between oil and equity prices. Whilst it is true that such effects might not be that large, they could trigger larger effects due to known market over-reactions.

Overall, the empirical evidence suggests that the relationship between real oil and stock prices is not stable over time. As such, the recent perverse relationship between equity returns and oil price changes should not be taken as evidence that lower oil prices are bad for the real economy.

\subsection{Are lower oil prices beneficial for the US and the world econ- omy?}

Ideally we need to consider how oil prices and real activity are related (as opposed to equity markets). However, quarterly GDP series that exist are not sufficiently long for a reliable analysis of output-oil price relationship over different sub-periods, particularly the post-2008 crisis period. Also, unfortunately, there are no reliable monthly observations on aggregate real activity. While a number of investigators have used monthly measures of US manufacturing output, this is not sufficiently representative of an economy such as that of the US. 
Instead we use real dividends on S\&P 500 as a proxy for economic activity. The rationale is that if the demand for companies' products does not rise and they do not experience growth they cannot make profits, and if they do not have enough profits they could not pay dividends. While it is true that some companies strategically pay dividends even if their profitability is low, this can only be sustained in the short run (say one or two years). In the long run these companies need to be profitable in order to be able to continue paying out dividends. In other words, there has to be a relationship between real dividends and the economic climate in the long run.

Figure 9 shows the relationship between real oil prices and real dividends on the S\&P 500 over the last 71 years, from which we observe that generally lower (higher) oil prices have been associated with higher (lower) dividends. Table 2 reports the simple correlation between changes in real oil prices and dividends, clearly showing a negative relationship between them over all sub-periods. More specifically the relationships are statistically significant for the full sample (1946 to 2016), as well as the two sub-samples, 1981-2000 and 2011-2016, but not for the sub-period 1960-1980. More importantly we find that changes in real oil prices are negatively related to changes in real dividends over the post-2008 crisis period, and this relationship is also highly statistically significant.

Figure 9: Real Oil Prices and Real Dividends (S\&P 500), 1946M1-2016M3

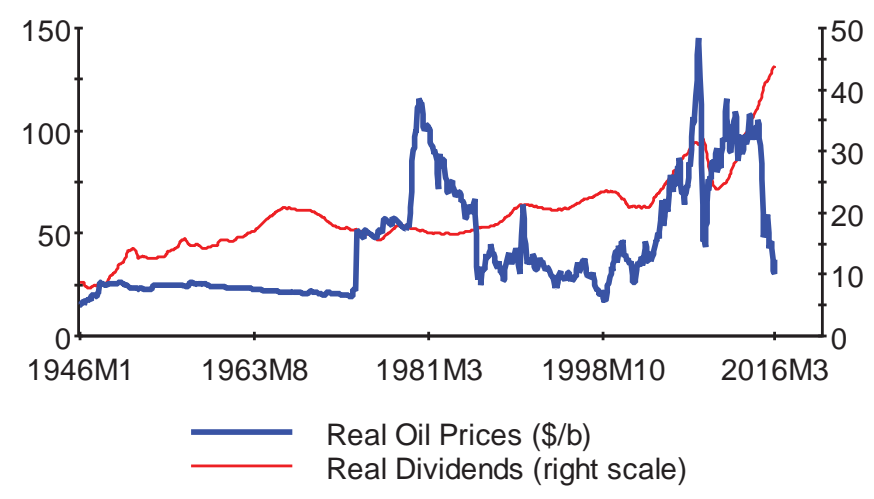

Data sources: Robert Shiller's online database, Federal Reserve Economic Data (FRED), and United States Energy Information Administration (EIA).

Using a relatively long monthly time series data on dividends and oil prices (1970-2016) we estimate rolling regressions (with 10-year windows) of the rate of change of real dividends on the rate of change of real oil prices, and plot the coefficient of the rate of change of real oil prices (blue solid) and its two standard error bands (red dashed) in Figure 10. As can 
be seen the rolling estimates of the coefficient of real oil price changes on dividends have been negative over the whole sample period, and statistically significantly negative for most of the period. Interestingly enough, the beneficial effects of lower oil prices on dividends have become even much stronger over the more recent episodes, with the rolling estimates becoming particularly large and statistically significant post 2009.

\section{Figure 10: Rolling Estimates of the Effects of Changes in Oil Prices on Real Dividends}

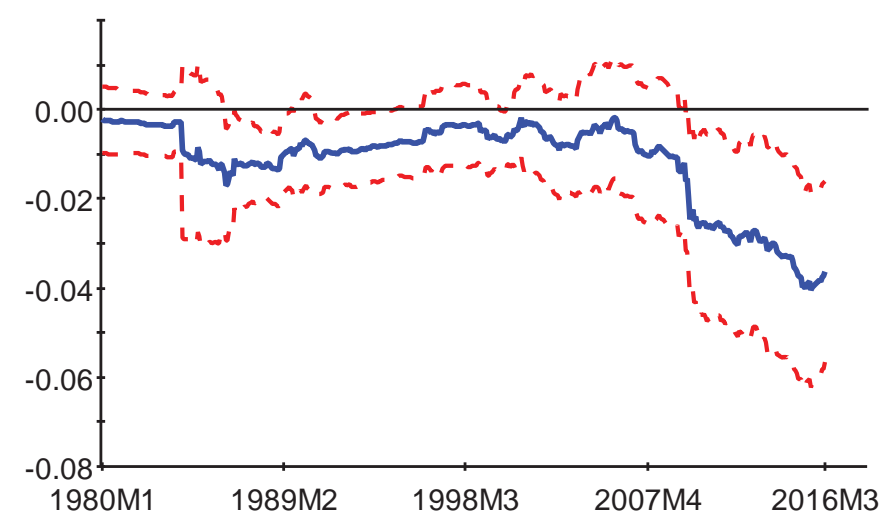

Notes: Rolling estimates of the coefficient of the rate of change of real oil prices and its two standard error bands based. Dependant variable is the rate of change of real dividends (S\&P 500). The window size is 120 months.

Data sources: Robert Shiller's online database, Federal Reserve Economic Data (FRED), and United States Energy Information Administration (EIA).

The rolling estimates give a clear indication of the changing nature of the relationships between oil prices, equity prices, and dividends, but do not allow for changing dynamics between these variables. Therefore, to check the robustness of the results to the dynamics of adjustments between oil price changes and the economy, we also estimated autoregressive distributed lag (ARDL) models, one with the rate of change of real equity and oil prices and another with the rate of change of real dividends and oil prices. ${ }^{8}$ Instead of rolling windows we estimated the ARDL models on the full sample period (1970M1 to 2016M4) and three sub-samples, namely 1970M1-1989M12, 1990M1-2007M12, and 2008M1-2016M4. We selected the lag order of the ARDL regressions with equity prices using the Akaike Information Criterion (AIC) with a maximum lag order set to 12. The estimates of the long-

\footnotetext{
${ }^{8}$ In a series of papers, Pesaran and Smith (1995), Pesaran (1997), and Pesaran, Shin, and Smith (1999) show that the traditional ARDL approach can be used for long-run analysis, and that the ARDL methodology is valid regardless of whether the regressors are exogenous, or endogenous, and irrespective of whether the underlying variables are $I(0)$ or $I(1)$.
} 
run coefficient of real oil prices are reported in panel (a) of Table 3, from which we can see that the coefficients are negative and statistically significant for the full sample and in two sub-samples (1970-1989 and 1990-2007), but the coefficient is positive and significant based on the 2008-2016 sub-sample. This provides further evidence for the unstable relationship between these two variables, and matches the results in Section 3.1 and Figure 8. Turning to the ARDL regressions with real dividends, we see that in all cases the coefficient of the oil price variable is negative, being statistically significant in all sub-samples even in the post-2008 period, see panel (b) of Table $3 .^{9}$ These results are in line with those using simple correlations in Table 2 and rolling estimates in Figure 10, and therefore suggest that lower oil prices are good for the US economy, even if we only consider the period after the Great Recession.

For completeness, we also considered different measures of monthly economic activity, namely US industrial production and manufacturing indices, which are widely used in empirical work with monthly data. As before we estimated ARDL models over the full sample and the three sub-samples, now between the oil price variable and these two new measures of economic activity. The results for the ARDL models with industrial production are reported in panel (c) and for the ones with manufacturing production in panel (d) of Table 3. The coefficient of the oil price variable is negative in all sample periods and for both activity measures, but they are statistically significant only for the full sample and the first sub-sample, 1970M1-1989M12, thus supporting the results in panel (b) of Table 3.

To summarize, unlike the relationship between equity and oil prices, we find a stable negative relationship between oil prices, dividends and monthly real activity measures such as industrial production, which supports the results from the GVAR-Oil model (see Figure 5 ), and does not support the view that lower oil prices have not been good for the US economy since the 2008 financial crises.

Nevertheless, the fall in oil prices has hit the major oil exporters the hardest given that almost all of them substantially expanded their welfare programs during the period of unusually high oil prices that preceded the current price falls. For instance, post-2011, the GCC countries increased their social spending by around $\$ 150$ billion. Saudi Arabia increased government employees pay and benefits by $\$ 93$ billion and similar increases in welfare were put into effect by other GCC countries (Bahrain, Kuwait, Oman, Qatar, and the UAE); see, for instance, Abdel Ghafar (2016) and Devarajan (2016). In Iran, despite the sanctions and the threat of more sanctions, the Ahmadinejad government initiated monthly

\footnotetext{
${ }^{9}$ In the case of the ARDL models with real dividends, we initially selected the lag orders using the AIC, however, given the smoothness of the real dividend series and given that AIC selected a large number of lags, the estimates were not reliable. We therefore based the lag order selection on the Schwarz Bayesian Criterion.
} 


\section{Table 3: Estimates of the Long-run Coefficients of Real Oil Prices based on Various ARDL Regressions and Sub-samples, 1970M1-2016M4}

1970M1-2016M4 1970M1-1989M12 1990M1-2007M12 2008M1-2016M4
(a) ARDL Model with Real Equity Prices
Oil Price Coefficient
$-0.159^{* *}$
$-0.176^{*}$
$-0.185^{* * *}$
$0.202^{*}$
$(0.039)$
$(0.118)$
ARDL Order
$(6,12)$
$(2,12)$
$(1,1)$
$(4,4)$

(b) ARDL Model with Real Dividends

$\begin{array}{lcccc}\text { Oil Price Coefficient } & -0.016 & -0.046^{* * *} & -0.092^{* *} & -0.111^{* *} \\ & (0.017) & (0.014) & (0.043) & (0.048) \\ \text { ARDL Order } & (1,3) & (2,1) & (5,0) & (1,0)\end{array}$

(c) ARDL Model with Industrial Production

$\begin{array}{lcccc}\text { Oil Price Coefficient } & -0.053^{* *} & -0.084^{* * *} & -0.019 & -0.098 \\ & (0.025) & (0.029) & (0.014) & (0.075) \\ \text { ARDL Order } & (12,11) & (2,11) & (3,3) & (12,10)\end{array}$

(d) ARDL Model with Manufacturing Production
Oil Price Coefficient
$-0.075^{* * *}$
$(0.027)$
$-0.116^{* * *}$
(0.036)
$-0.022$
$-0.067$
$(3,11)$
$(2,11)$
$(0.017)$
$(0.063)$
ARDL Order
$(3,3)$
$(12,8)$

Notes: Symbols $* * *, * *$, and $*$ denote significance at 1\%,5\%, and $10 \%$ levels, respectively. The lag order of the ARDL regressions with real equity prices, industrial and manufacturing production indices were selected using the Akaike Information Criterion with a maximum lag order set to 12 . For the ARDL models with real dividends the lag order was selected using the Schwarz Bayesian Criterion; see also footnote 9.

Data sources: Robert Shiller's online database, Federal Reserve Economic Data (FRED), and United States Energy Information Administration (EIA). 
cash payments to all households irrespective of their income or wealth, and raided the oil stabilization fund (rather than enhancing it) to partly pay for the program; see Mohaddes and Pesaran (2014). It is not surprising therefore that the fall in oil prices has forced oil exporters to cut back on their welfare programs, withdraw from their oil funds, and attempt to diversify their economies.

At the world level, however, we would expect the increase in spending by oil importers to exceed the decline in expenditure by oil exporters (given their different marginal propensities to consume/invest), and so eventually lower oil prices should also be beneficial for the world economy. This was also clearly illustrated within the GVAR-Oil framework in Section 2.2; see, in particular, the responses of global and country level GDPs following a fall in oil prices in Figures 2 and 5. This in turn implies that demand for energy is going to start to rise, which will put upward pressure on oil prices in the medium term, and the equilibrating process starts to take place.

\section{$4 \quad$ How do global oil supplies respond to lower oil prices?}

On the supply side, the response to price changes is likely to differ markedly across major oil producers. Non-OPEC oil exporters, particularly US oil producers, tend to respond reasonably quickly and positively (negatively) to oil price rises (falls). As noted earlier, US production had been rising since 2008, but peaked around April 2015 (at 9.45 million b/d) and since then, with continued low oil prices, has fallen to 8.80 million b/d in the first week of May 2016 (see Figure 6). This large fall in oil production is mainly due to the fact that unconventional oil (which now forms around half of US oil output) tends to respond to oil price changes very much like any other manufacturing process. In fact, since mid-2014 the number of US oil and gas companies that have filed for bankruptcy has now reached 59, and is expected to rise further, soon overtaking the 68 bankruptcies that were filed at the peak of the dot-com bust in 2002-2003 (see Reuters on 4 May, 2016). Moreover, the European Central Bank recently estimated that energy related investments in the United States have fallen by $65 \%$ cumulatively since mid-2014, with the energy sector contribution to GDP growth in the US being overall negative.

In contrast to the US, oil production from OPEC is likely to be less responsive to price changes, with political factors playing a significant role in the process. It has long been argued, dating back to the first oil crisis of 1973/74, that major oil exporters that heavily depend on oil revenues, set their oil production to achieve a given level of oil revenues (the so-called target revenue model, see Bénard (1980), Crémer and Salehi-Isfahani (1980), and Teece (1982)), and as a result respond perversely to price changes. The result is a backward- 
bending supply curve where a sustained fall in oil prices can lead to increased oil production from some OPEC member countries who own large reserves of low cost oil, a demanding welfare program, and a fragile political system.

Figure 11: Monthly Oil Production for Iran, Iraq, Russia, Saudi Arabia, and the US (1000 barrels/day)

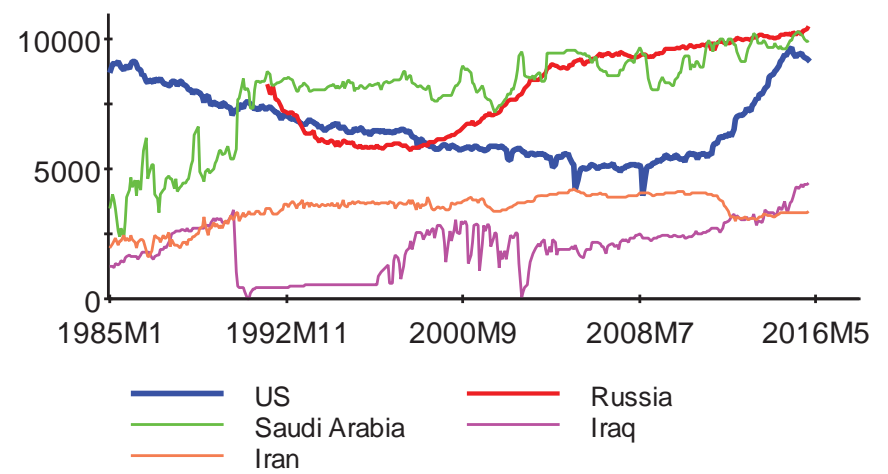

Data sources: United States Energy Information Administration (EIA).

Amongst the non-OPEC producers, Russia has continued to increase production - behaving very much as predicted by the target revenue model, see Figure 11. Canada's production has become more volatile but continues to show a rising trend. Oil production in Norway and Mexico has stabilized following a downward trend since early 2000. Overall, despite falling oil prices, oil production has continued to rise world-wide, with OPEC and nonOPEC contributing to the rise, almost equally in 2015. For now, only US production from unconventional oil has been declining under pressure from lower oil prices. However, according to the International Energy Association (IEA) global upstream oil and gas investment has been falling by around $23 \%$ and 19\% in 2014 and 2015 respectively, and BP reported recently that oil and gas investments fell by $\$ 160$ billion in 2015 and is expected to fall by another $\$ 50$ billion in 2016; this in turn will have implications for future supply.

There is an important analogy between the Ricardian theory of rent on agricultural land and modelling of oil prices. Ricardo (1817) observed that rent rises as land of lower quality are brought under cultivation in conditions of rising demand for agricultural products. In the same way, profit from productive oil fields rise as costlier fields are brought into production. With significant heterogeneity of breakeven production costs across fields in different parts of the world, as well as across different types of oil fields within a given region, it is not 
surprising that it is the production of the high cost unconventional oil that is first to be negatively affected by lower oil prices. If over the next year or so current low oil prices prevail, further production cut backs from such fields are to be expected, in particular for the US oil production which is expected to gradually adjust downward.

\section{Concluding remarks}

As with all markets, lower oil prices will eventually lead to higher demand and lower supplies. The beneficial income effects of lower oil prices will show up in higher oil demand by oil importers including the US, while the loss of revenues by oil exporters will act in the opposite direction, but the net effect is likely to be positive. On the supply side, the effects of lower prices are mixed with the US production falling and OPEC production rising (mainly from Saudi Arabia and Iraq). The rise in OPEC production initially appears to be counterintuitive, but reflects the fact that some of the major oil producers try to compensate their loss of revenues by raising production. This means that oil markets equilibrate, but very slowly. Oil prices are likely to fluctuate within a wide range, the ceiling being the marginal cost for US shale oil producers (around $\$ 60$ per barrel). This episodic process gets further accentuated by new reserve discoveries, technological advances in oil production and alternative energy sources. 


\section{References}

Abdel Ghafar, A. (2016). Will the GCC be able to Adjust to Lower Oil Prices? Adel Abdel Ghafar's Blog on Brookings posted on February 18, 2016.

Baffes, J., M. A. Kose, F. Ohnsorge, and M. Stocker (2015). The Great Plunge in Oil

Prices: Causes, Consequences, and Policy Responses. World Bank Policy Research Note PRS/15/01.

Bernanke, B. (2016). The Relationship Between Stocks and Oil Prices. Ben Bernanke's Blog on Brookings posted on February 19, 2016.

Bénard, A. (1980). World Oil and Cold Reality. Harvard Business Review 58, 90-101.

Cashin, P., K. Mohaddes, and M. Raissi (2015). Fair Weather or Foul? The Macroeconomic Effects of El Niño. IMF Working Paper WP/15/89.

Cashin, P., K. Mohaddes, and M. Raissi (2016). China's Slowdown and Global Financial Market Volatility: Is World Growth Losing Out? IMF Working Paper WP/16/63.

Cashin, P., K. Mohaddes, M. Raissi, and M. Raissi (2014). The Differential Effects of Oil Demand and Supply Shocks on the Global Economy. Energy Economics 44, 113-134.

Chudik, A. and M. H. Pesaran (2016). Theory and Practice of GVAR Modeling. Journal of Economic Surveys 30(1), 165-197.

Crémer, J. and D. Salehi-Isfahani (1980). A Theory of Competitive Pricing in the Oil Market: What Does OPEC Really Do? CARESS Working Paper 80-4, University of Pennsylvania, Philadelphia..

Dees, S., F. di Mauro, M. H. Pesaran, and L. V. Smith (2007). Exploring the International Linkages of the Euro Area: A Global VAR Analysis. Journal of Applied Econometrics 22, $1-38$.

Devarajan, S. (2016). How the Arab World Can Benefit from Low Oil Prices. Presentation at the "Oil, Middle East, and the Global Economy Conference" at the University of Southern California on April 2, 2016.

Hamilton, J. D. (2009). Causes and Consequences of the Oil Shock of 2007-08. Brookings Papers on Economic Activity, Economic Studies Program, The Brookings Institution 40(1), 215-283. 
Jones, C. M. and G. Kaul (1996). Oil and the Stock Markets. The Journal of Finance 51(2), 463-491.

Kilian, L. (2009). Not All Oil Price Shocks Are Alike: Disentangling Demand and Supply Shocks in the Crude Oil Market. The American Economic Review 99(3), 1053-1069.

Mohaddes, K. and M. H. Pesaran (2014). One Hundred Years of Oil Income and the Iranian Economy: A Curse or a Blessing? In P. Alizadeh and H. Hakimian (Eds.), Iran and the Global Economy: Petro Populism, Islam and Economic Sanctions. Routledge, London.

Mohaddes, K. and M. H. Pesaran (2015). Country-Specific Oil Supply Shocks and the Global Economy: A Counterfactual Analysis. USC-INET Research Paper No. 15-14.

Mohaddes, K. and M. Raissi (2015). The U.S. Oil Supply Revolution and the Global Economy. IMF Working Paper No. 15/259.

Obstfeld, M., G. M. Milesi-Ferretti, and R. Arezki (2016). Oil Prices and the Global Economy: It's Complicated. iMFdirect blog posted on March 24, 2016.

Pesaran, M. H. (1997). The Role of Economic Theory in Modelling the Long Run. The Economic Journal 107(440), 178-191.

Pesaran, M. H., T. Schuermann, and S. Weiner (2004). Modelling Regional Interdependencies using a Global Error-Correcting Macroeconometric Model. Journal of Business and Economics Statistics 22, 129-162.

Pesaran, M. H., Y. Shin, and R. P. Smith (1999). Pooled Mean Group Estimation of Dynamic Heterogeneous Panels. Journal of the American Statistical Association 94 (446), 621-634.

Pesaran, M. H. and R. Smith (1995). Estimating Long-run Relationships from Dynamic Heterogeneous Panels. Journal of Econometrics 68(1), 79-113.

Ricardo, D. (1817). On the Principles of Political Economy and Taxation (First ed.). London: John Murray.

Teece, D. (1982). OPEC Behavior: An Alternative View. In J. M. Griffin and D. Teece (Eds.), OPEC Behavior and World Oil Prices, pp. 64-93. Allen and Unwin, London.

Wei, C. (2003). Energy, the Stock Market, and the Putty-Clay Investment Model. American Economic Review 93(1), 311-323. 